\title{
A Technological Study of Reduced Iron from Standard Concentrate
}

\author{
Unursaikhan Buyannasan ${ }^{1}$, Sukhbat Sandag-Ochir ${ }^{1}$, Sugir-Erdene Namsrai ${ }^{1}$, \\ Soyolmaa Tsolkhuu ${ }^{1}$, Orgilbayar Batkhuyag ${ }^{1}$, Baasanjav Dashtseren ${ }^{1}$, \\ Zagarzusem Tsedendamba ${ }^{1}$, Khasbaatar Dashkhuu $^{1,2}$, Otgonjargal Enkhtur ${ }^{1, *}$ \\ ${ }^{1}$ Institute of Chemistry and Chemical Technology, Mongolian Academy of Sciences, Ulaanbaatar, 13330, \\ Mongolia \\ ${ }^{2}$ Department of Chemical and Biological Engineering, School of Engineering and Applied Sciences, National \\ University of Mongolia \\ *Corresponding author. Email: otgonjargale@mas.ac.mn
}

\begin{abstract}
The gas-based direct reduction of iron concentrate pellets was carried out by using the typical carbon monoxide. The investigation on the influences of time and temperature of the reduction were studied. The results showed that the temperature and time of the reduction were directly related to the reduced iron content. In order to perform the iron reduction experiment, the powder iron concentrate needed to be pelletized, and the binder agents have used molasses and bentonite. As the result of the reducing experiment at the $1050^{\circ} \mathrm{C}$ temperature and for 120 minutes, the reduced iron content was $85.6 \%$, and hardness was $115.5 \mathrm{HV}$ which meets the requirements of the reduced iron standard.
\end{abstract}

Keywords: Direct reduction, Reduced iron, Binder, Pellet, Reducing gas

\section{INTRODUCTION}

The 16 regions of iron deposits are in Mongolian territory. The deposits reserve of A $+\mathrm{B}+\mathrm{C}$ grade are estimated at 1 billion tons in a zonal frame. The total resources are calculated at 5.5 billion tons. About 300 deposits, occurrences, and mineralization points with an average iron content of $20-55 \%$ have been identified [1]. Mongolia exports iron concentrate with $62-65 \%$ iron content by primary processing of iron ore. In order to develop the ferrous metallurgy industry, it is necessary to produce metalized iron. High-quality iron ore or concentrate is used to extract reduced iron at a temperature of $<1050^{\circ} \mathrm{C}$. Direct Reduced Iron (DRI) is the product of the direct reduction of iron ore in the solid-state by carbon monoxide and hydrogen derived from natural gas or coal. Iron pellets should have high-grade properties, good intensity, and uniform granularity for beneficial furnace burden in the ironmaking process. An acidic pellet can be combined with a highly basic pellet to form an appropriate burden structure [2]. For decades, hundreds of minerals and clays (mostly silicate-based binders) have been applied as alternative binders in the production of iron ore pellets. They have been found to provide sufficient strength to iron ore pellets. Binders not only help improve pellet strength but also control the moisture content. The absorbed moisture contents of molassesadded pellets were $4.0 \%$ lower than those of bentonite-added pellets. The reduction in moisture content with the use of molasses binder will decrease energy consumption during drying [3]. There has been a rapid increase in iron production via the direct reduced process over the past 15 years. DRI technology is dominated by the MIDREX and HYL processes.

In the MIDREX process, the iron oxide feed descends in a cylindrical shaft furnace and is heated and reduced by rising hot reducing gas. The basic HYL process employs a conventional natural gassteam reformer for reducing gas generation. This process removes oxygen from the iron ore by chemical reactions based on $\mathrm{H}_{2}$ and $\mathrm{CO}$ from the gassteam reformer [4]. Most of the DRI technologies 
developed so far use $\mathrm{CO}$ as the major reducing gas $[5,6]$. Carbon monoxide is a gas that is used as a reducing agent in ferroalloy industries and DRI plants. Carbon monoxide occurs as a significant product gas in carbothermic processes, especially in electric furnaces. Recirculation of the $\mathrm{CO}$ gas can reduce the coke demand by up to $45 \%[6,7,9]$. Carbon monoxide is a potent reducing agent. It is also useful as a metallurgical reducing agent because it reduces many metal oxides to the elemental metal at high temperatures $[8,10]$. The gas-based reduction process with the advantages of mature technology and increased productivity is the main one in the direct reduction process [9]. Steel is an alloy consisting primarily of iron and less than $2 \%$ carbon. Therefore, iron ore is essential for steel production, vital to maintaining a strong industrial base [10]. Due to its pure and stable composition, DRI is considered the perfect material for electric arc furnace (EAF) steelmaking $[9,11]$.

In this study, a distinctive feature of our approach is that the iron concentrate of the Tumur Tolgoi deposit derives DRI, whereas aimed to develop a novel scientific framework for the efficient conversion of carbon monoxide reducing agents used for reduced iron concentrate in a reduction reactor.

\section{EXPERIMENTAL}

\subsection{Materials}

The standard iron concentrate used in this study was obtained from the Tumur Tolgoi deposit in Mongolia. The standard iron concentrate, which the iron content was $66.2 \%$, and the sulfur content $0.4 \%$.

The gas for reductive roasting was carbon monoxide, and the purity of this gas was above 99.99\%, which was obtained from China. The molasses and bentonite binders selection was based on the literature. The most common types of binders that have been considered for iron concentrate pelletization were used in the experiments. Binder agents were obtained from Sinopharm Chemical Reagents., LTD.

\subsection{Methods}

\subsubsection{Pelletization Process of Standard Iron Concentrate}

The standard iron concentrate (fines) resulting from the concentration process must be agglomerated for use in iron and steelmaking [12]. The fines were pelletized according to GOST 17212-84, and binder reagents were used. The TDYZ-600 pelletizer was used for the pelletization process. Ground iron concentrate of typical size $80 \% 74$ microns must be at 7-9\% moisture. A suitable binder (Bentonite and Molasses) is added to the concentrate and thoroughly mixed in a high-intensity mixer. Additional water is sprayed onto the disc in which the material is coagulated and forms into pellets by a continuous rotary motion. Green pellets with a size range of 12 $16 \mathrm{~mm}$ were prepared in pelletizing discs. The disc is an inclined pan of around 0.6 meters diameter rotating at about $43 \mathrm{rpm}$, working area of $0.28 \mathrm{~m}^{2}$. The inclination of a disc is around $60^{\circ}$. Then green pellets keeping in a muffle oven (SNOL) at $1050^{\circ} \mathrm{C}$. The pellets were subjected to determine the compressive strength, place the pellets on a flat steel plate and apply even pressure until cracks appeared on the surface of the pellets.

\subsubsection{The Reduction Process of Standard Iron Concentrate}

The reduction process was performed using a reduction reactor CGF-1100 manufactured in China. First, make sure the safe operation mode of the reduction furnace, adjust the test data, and then switch on the reduction furnace. Reducing iron concentrate: use green pellet concentrate above $>65 \%$ content. Initially, when the reducing furnace was heated, gradually increase the temperature for 30 min. Then, place the prepared green pellets in the furnace that has reached the reducing temperature, adjust the reducing time, and open the reducing gas tube. A gas velocity of $\mathrm{CO}$ was $3 \mathrm{~L} / \mathrm{min}$. The temperature was $850^{\circ} \mathrm{C}$ to $1050^{\circ} \mathrm{C}$, and the experimental duration was 60-120 minutes. During the reduction process, the gas inlet and outlet pipes, the cooling water were checked regularly. At the end of the test, switched off the reduction furnace and the cooling water consumption must be increased to 2 $\mathrm{L} / \mathrm{min}$ for the purpose cool the sample in the reactor.

The reduction of standard iron concentrate was carried out according to the following technological scheme (Figure 1).

\subsubsection{Analysis}

The mineral composition of the standard iron concentrate by X-ray diffractometer (Philips PW1800) and analysis of the elements performed by inductively coupled plasma optical emission spectrometry (ICP-OES) (Thermo Scientific iCAP 7200 ICP-OES Duo - Thermo Fisher Scientific). The 
hardness of reduced pellets was determined by a LEEB durometer (UWN-520).

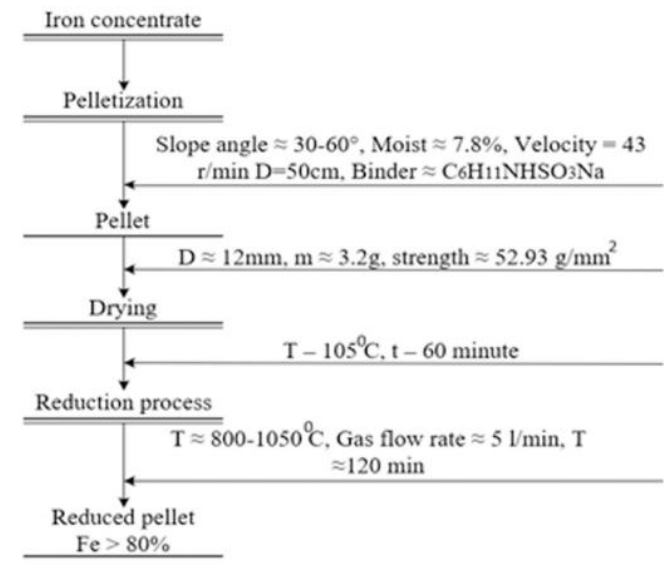

Figure 1. Flowsheet for reducing iron concentrate

\section{RESULTS AND DISCUSSIONS}

\section{1. $X R D$}

According to chemical analysis, the content of the concentrated iron was $66.2 \%$, the sulfur content was $0.4 \%$, and the phosphorus content was less than $0.01 \%$. The results of the X-ray diffraction analysis of the iron concentrate are shown in Figure 2.

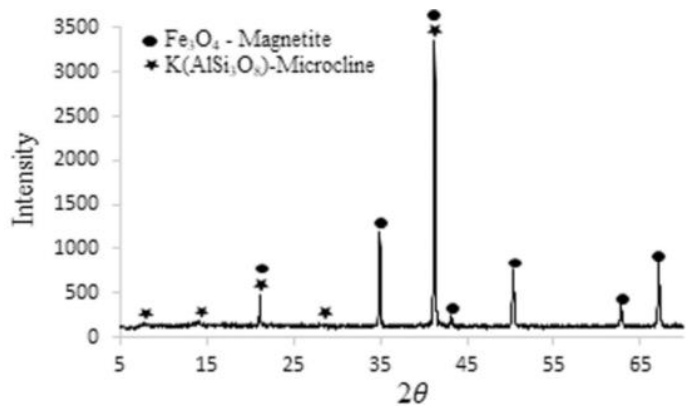

Figure 2. XRD results of iron concentrate

The XRD phase of iron concentrate shown in Figure 2 was seen from graphics that magnetite and microcline phases formed. This suggests that it is suitable for reducing iron concentrate.

\subsection{Result of Pelletization}

When the green pellet samples were prepared with the strength of depending on the binder contents with molasses taken in percentages $1 \%, 3 \%, 5 \%, 7 \%$, the bentonite taken in percentages $0.5 \%, 1 \%, 1.5 \%$, $2 \%$, those average strength parameters were determined in Figure 3.

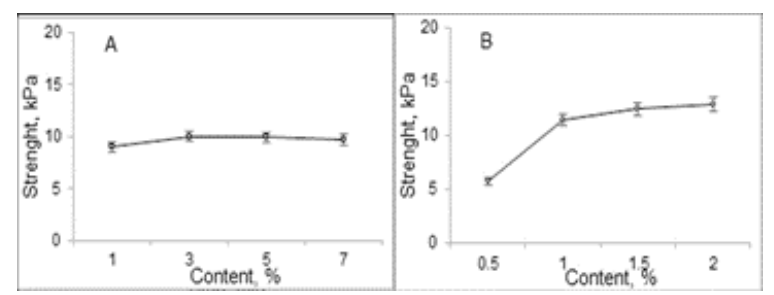

Figure 3. Strength index depending on the content of binder (A) molasses, (B) bentonite

Technically, the strength of the binders increases with rising bentonite content. However, the bentonite was a negative effect on iron content after the reduction process. Bentonite is one of the most used binders with favorable mechanical and metallurgical pellet properties. Bentonite contains impurities, mainly silica and alumina. While organic binders provide sufficient wet and dry pellet strengths, inorganic salts provide the required preheated and fired pellet strengths [12]. So, we selected the optimum strength was obtained of $10 \mathrm{kPa}$ at $3 \%$ molasses.

\subsection{Result of the Reduction Process}

The iron concentrate was pelletized, and the DRI process was carried out in a reduction furnace (reactor) using carbon monoxide (CO). The iron concentrate was reduced as following three steps by reaction with $\mathrm{CO}$ in the reactor at temperatures between $850^{\circ} \mathrm{C}$ and $1050^{\circ} \mathrm{C}$. In the reactor, the following chemical reaction occurs:

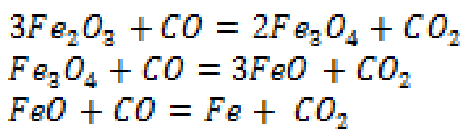

The $\mathrm{Fe}_{2} \mathrm{O}_{3}$ reduction initiated below $580^{\circ} \mathrm{C}$, and has completed by $670^{\circ} \mathrm{C}$. The $\mathrm{Fe}_{3} \mathrm{O}_{4}$ was reduced between $670^{\circ} \mathrm{C}$ and $870^{\circ} \mathrm{C}$ to form $\mathrm{FeO}$. The $\mathrm{FeO}$ was reduced after that by $\mathrm{CO}$ generated predominantly from carbon gasification. The reduction of iron oxides was almost completed by $1200^{\circ} \mathrm{C}$, resulting in metallic iron formation [13].

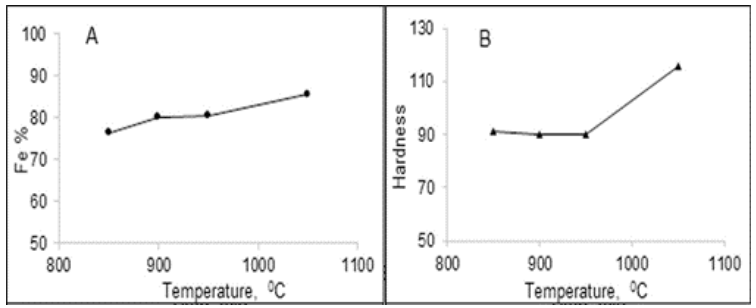

Figure 4. (A) The curve is dependent on reducing the temperature, (B) Vickers hardness 
Table 1. Chemical composition of reduced iron, $\%$

\begin{tabular}{|l|l|l|l|l|l|l|l|l|l|l|l|}
\hline \multirow{2}{*}{ Sample } & \multicolumn{9}{l|}{ Chemical composition, \% } \\
\cline { 2 - 14 } & $\mathrm{Al}$ & $\mathrm{Mg}$ & $\mathrm{Ca}$ & $\mathrm{K}$ & $\mathrm{Ti}$ & $\mathrm{Si}$ & $\mathrm{O}$ & $\mathrm{C}$ & Other & $\mathrm{Fe}$ & Total \\
\hline Reduced iron & 0.39 & 2.63 & 0.3 & 0.05 & 0.1 & 2.8 & 7.01 & 0.02 & 1.1 & 85.6 & 100 \\
\hline
\end{tabular}

It can be observed that the reduction temperature has a significant impact on the reduction process. By increasing the temperature from $850^{\circ} \mathrm{C}$ to $1050^{\circ} \mathrm{C}$ under reducing gas flow rate $3 \mathrm{~L} / \mathrm{min} \mathrm{CO}$, reduced iron content increases distinctly from $76.44 \%$ to $85.6 \%$. The hardness of the reduced pellets was determined by the Vickers method, and the test result is shown in Figure 4B. The hardness of the pellets reduced at $1050^{\circ} \mathrm{C}$ reached $115.5 \mathrm{HV}$, while between $850^{\circ} \mathrm{C}$ and $950^{\circ} \mathrm{C}$ it ranged from $90 \mathrm{HV}$ to $91.5 \mathrm{HV}$.

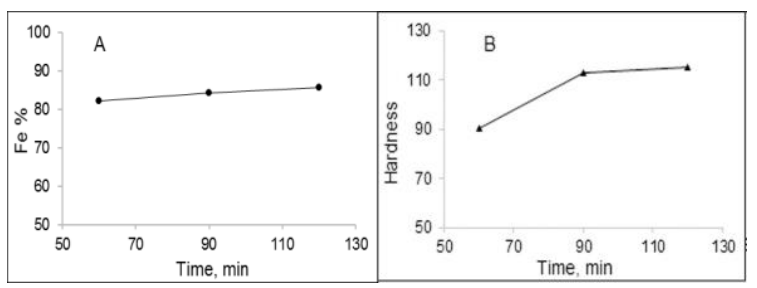

Figure 5. (A) The curve is dependent on reducing time, (B) Vickers hardness

The reduction of standard iron concentrate as a function of reducing time is shown in Figure 5A. Reduction temperature was carried out at $1050^{\circ} \mathrm{C}$ for various duration periods from 60 to $120 \mathrm{~min}$. It is found that for each reduction value, reduced iron content increases slightly from $82.12 \%$ to $85.6 \%$ when it was reduced at decreasing the gas flow rate of $3 \mathrm{~L} / \mathrm{min} \mathrm{CO}$. Depending on the reducing time, the hardness of the pellets was $90.3 \mathrm{HV}, 113 \mathrm{HV}$, and $115.5 \mathrm{HV}$ at 60,90 , and $120 \mathrm{~min}$, respectively. Therefore, for $120 \mathrm{~min}$ at $1050^{\circ} \mathrm{C}$ the contained the reduced iron was $85.6 \%$, and the hardness was 115.5 $\mathrm{HV}$, which led to the production of reduced iron which meets the requirements of the optimal mode and standard.

DRI was obtained when iron oxide was reduced to metallic form in the solid-state. Since there is no melting, the external shape is retained. Figure 6 demonstrated reduced iron color changed from black to gray. The reduced iron density ranges from about $3.7 \cdot 10^{3}$ to $4.8 \cdot 10^{3} \mathrm{~kg} / \mathrm{m}^{3}$. Thus, there was about 40 $50 \%$ reduction in volume and this is manifested in the formation of pores throughout the interior of reduced iron pieces.

Based on the results of ICP-OES and X-ray fluorescence analysis in the reduction products, the iron content in Table 1 is $85.6 \%$ which is considered sufficient.
The low-temperature reduction process a vital role in ferroalloy industries since the pellet composition, time-temperature, and reaction environment affect the properties of carbon monoxide. The direct reduced iron yield depending on iron concentrate, reduction time, temperature, and gas flow rate are important parameters for using $\mathrm{CO}$ reducing agent.

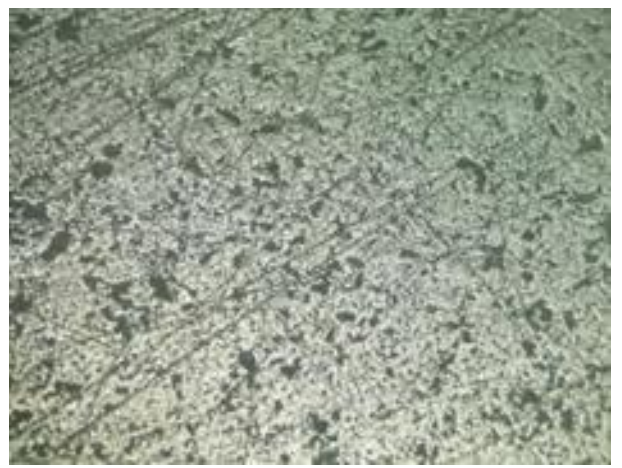

Figure 6. Micro-image of reduced iron extracted from the iron concentrate on Tumur Tolgoi deposit (scale $4 x, F e$ - pure iron)

\section{CONCLUSION}

Direct reduced iron technology extracts $\mathrm{CO}$ from natural gas and coal, which is an advantage of traditional methods. Iron concentrate with a grade of more than $65 \%$ from the Tumurtolgoi deposit was obtained reduced iron by direct reduction technology. The influence of temperature and duration of the DRI process was investigated. As the result of the reducing conditions at the $1050^{\circ} \mathrm{C}$ temperature and for $120 \mathrm{~min}$, the reduced iron content was $85.6 \%$, and hardness was $115.5 \mathrm{HV}$ which meets the requirements of the reduced iron standard. The direct reduced iron yield, such as iron concentrate, reduction time, temperature, and gas flow rate, are important parameters for using $\mathrm{CO}$ reducing agents.

\section{ACKNOWLEDGMENTS}

Experimental and analytical support of the Institute of Chemistry and Chemical Technology of the Mongolian Academy of Sciences is gratefully acknowledged. 


\section{REFERENCES}

[1] Unursaikhan B., Baasanjav D., Sugir-Erdene N., Orgilbayar B., Sukhbat S., et.al., (2019) Technological study of iron ore processing from Chandmani-Uul deposit by dry and wet magnetic separation. Bulletin of the Institute of Chemistry and Chemical Technology, Vol. 7, 12-17. DOI: /10.5564/bicct.v0i7.1267

[2] Liu H., Bing X., Yue-lin Q., (2017) Effect of bentonite on the pelleting properties of iron concentrate. Journal of chemistry, DOI: $\underline{10.1155 / 2017 / 7639326}$

[3] Kotta, Anand B., et al., (2019) Effect of molasses binder on the physical and mechanical properties of iron ore pellets. International Journal of Minerals, Metallurgy, and Materials, Vol. 26, 41-51. DOI: /10.1007/s12613-0191708-x

[4] Feinman J., Donald R.M.R., (1999) Direct reduced iron. Technology and economics of production and use.

[5] Nyankson E., Kolbeinsen L., (2015) Kinetics of direct iron ore reduction with $\mathrm{CO}-\mathrm{H}_{2}$ gas mixtures. International Journal of Engineering Research and Technology, Vol. 4, 934-940. DOI: 10.17577/IJERTV4IS040955

[6] Chunbao C.U., Da-qiang C., (2010) A brief overview of low $\mathrm{CO}_{2}$ emission technologies for iron and steel making. Journal of Iron and Steel Research, International, Vol.17(3), 1-7. DOI: /10.1016/S1006-706X(10)60064-7

[7] Funke A., Demus T., Willms T., Schenke L., Echterhof T., et al., (2018) Application of fast pyrolysis char in an electric arc furnace. Fuel Processing Technology, Vol. 174, 61-68. DOI: 10.1016/j.fuproc.2018.02.013

[8] Julien P., Jeffrey M.B., (2017) Enabling the metal fuel economy: green recycling of metal fuels. Sustainable Energy and Fuels, Vol. 1, 615-625.

[9] Yi L., Huang Z. Peng H., Jiang T., (2012) Action rules of $\mathrm{H}_{2}$ and $\mathrm{CO}$ in gas-based direct reduction of iron ore pellets. Journal of Central South University, Vol. 19.8, 2291-2296. DOI: 10.1007/s11771-012-1274-0

[10] Otto A., Robinius M., Grube T., Schiebahn S., Praktiknjo A., Stolten D., (2017) Power-toSteel: Reducing $\mathrm{CO}_{2}$ through the Integration of Renewable Energy and Hydrogen into the
German Steel Industry. Energies, Vol. 10, 451471. DOI: $10.3390 /$ en10040451

[11] Xuan Y., Qiang Y., (2016) Forecast of steel demand and the availability of depreciated steel scrap in China. Resources, Conservation and Recycling, Vol. 109, 1-12. DOI: /10.1016/j.resconrec.2016.02.003

[12] de Moraes., Sandra L., José R.B., de Lima., Tiago R.R., (2018) Iron ore pelletizing process: An Overview. Iron Ores and Iron Oxide Minerals, 41-59.

[13] Dutta S. K., Rameshwar S., (2016) Direct Reduced Iron: Production. Encyclopedia of Iron, Steel, and Their Alloys, 1082-1108. DOI: /10.1081/E-EISA-120050996 